\title{
Memristive electronic synapses made by anodic oxidation
}

Shaochuan Chen ${ }^{1,2}$, Seyedreza Noori ${ }^{3}$, Marco A. Villena ${ }^{1,4}$, Yuanyuan Shi ${ }^{5}$, Tingting Han ${ }^{1}$, Ying Zuo $^{1}$, MariaPia Pedeferri ${ }^{3}$, Dmitri Strukov ${ }^{2}$, Mario Lanza $^{1 *}$, Maria Vittoria Diamanti ${ }^{3}$

${ }^{1}$ Institute of Functional Nano and Soft Materials, Collaborative Innovation Center of Suzhou Nanoscience \& Technology, Soochow University, Suzhou 215123, China

${ }^{2}$ Department of Electrical and Computer Engineering, University of California at Santa Barbara, Santa Barbara, CA 93106-9560, USA

${ }^{3}$ Department of Chemistry, Materials and Chemical Engineering “G. Natta”, Politecnico di Milano, Via Mancinelli 7, Milan 20131, Italy

${ }^{4}$ Department of Electrical Engineering, Stanford University, Stanford, CA 94305, USA

${ }^{5}$ Andrew and Erna Viterbi Faculty of Electrical Engineering, Technion - Israel Institute of Technology, Haifa 32000, Israel

* Correspondence and requests for materials is addressed to Mario Lanza (Email: mlanza@suda.edu.cn) 

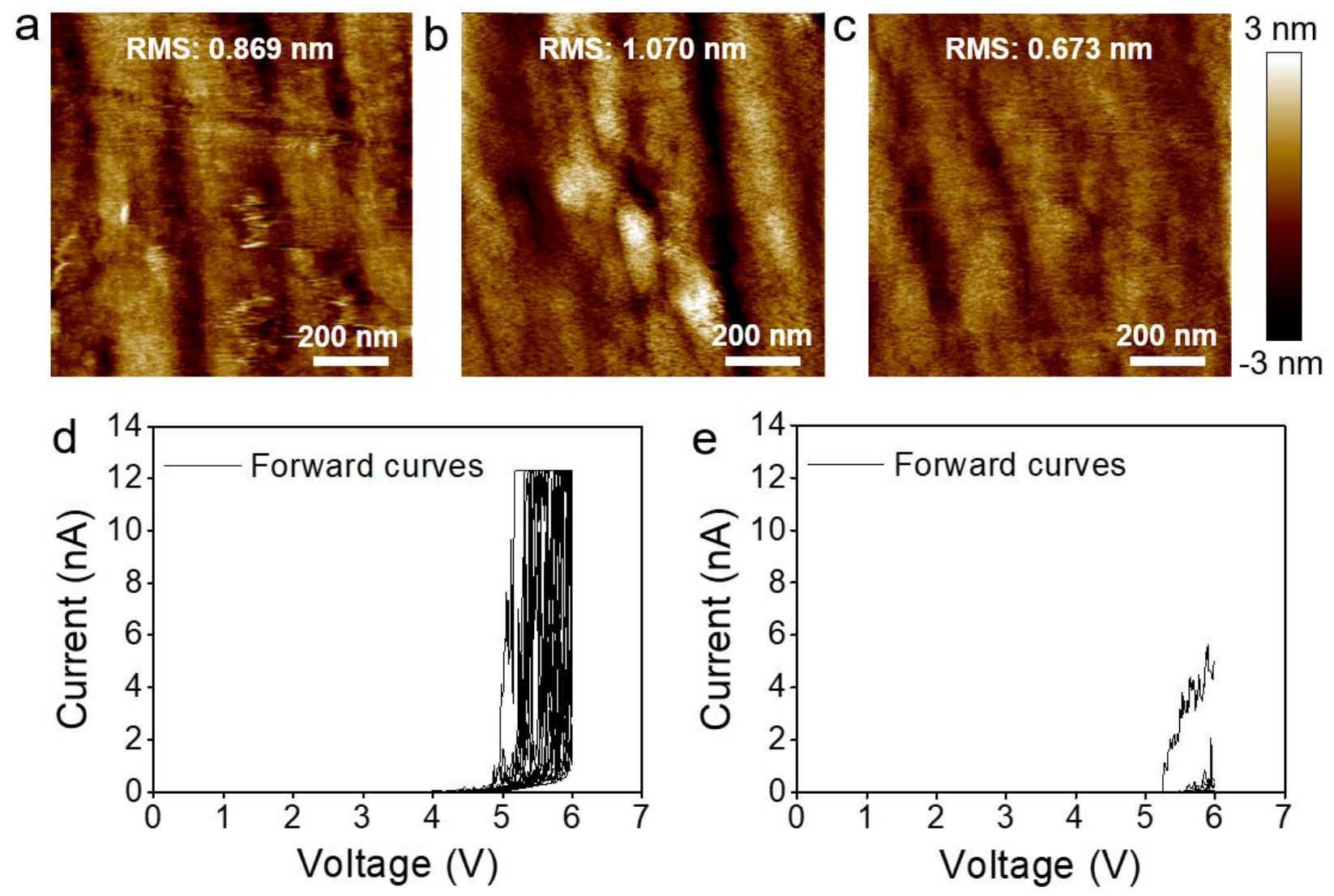

Supplementary Figure S1: (a-c) Topographic maps of $1 \mu \mathrm{m} \times 1 \mu \mathrm{m}$ titanium oxide films anodized at $2.5 \mathrm{~V}$ by using $0.5 \mathrm{M} \mathrm{H}_{3} \mathrm{PO}_{4}, 0.5 \mathrm{M} \mathrm{NaOH}$, and $0.5 \mathrm{M} \mathrm{NH}_{4} \mathrm{H}_{2} \mathrm{PO}_{4}$ electrolytes, respectively. (d) Sequences of $25 \mathrm{I}-\mathrm{V}$ curves collected $10 \mathrm{~nm}$ titanium oxide film $\left(2.5 \mathrm{~V}, \mathrm{H}_{3} \mathrm{PO}_{4}\right)$, the data show very low variability of onset voltages. (e) Sequences of $25 \mathrm{I}-\mathrm{V}$ onset curves collected $20 \mathrm{~nm}$ titanium oxide film $\left(7.5 \mathrm{~V}, \mathrm{H}_{3} \mathrm{PO}_{4}\right)$, which shows much higher resistance due to the increase of thickness. 


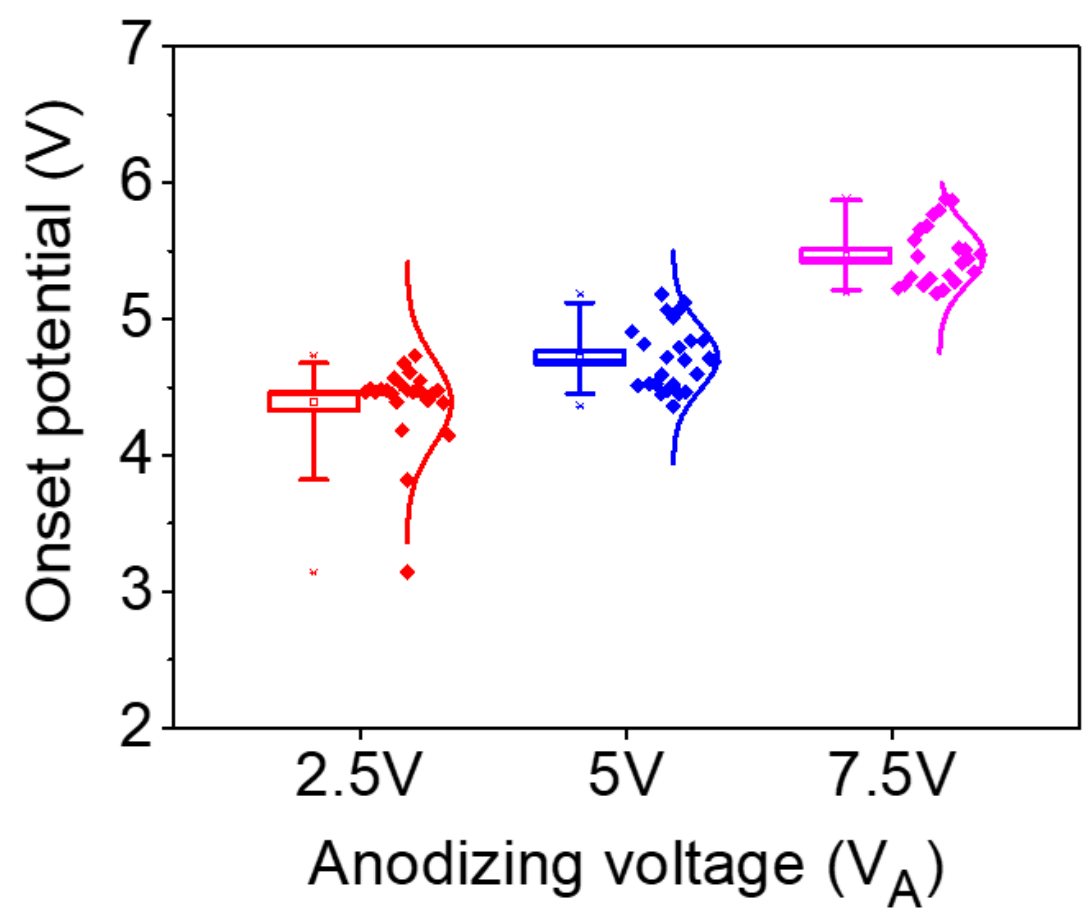

Supplementary Figure S2: Statistic distribution of the onset potentials $\left(\mathrm{V}_{\mathrm{ON}}\right)$ extracted from sequences of I-V curves collected on 25 different locations in all anodic devices $\left(\mathrm{V}_{\mathrm{A}}=2.5 \mathrm{~V}, 5 \mathrm{~V}\right.$ and $7.5 \mathrm{~V}, \mathrm{H}_{3} \mathrm{PO}_{4}$ ) using $10 \mathrm{pA}$ as current levels. The value of $\mathrm{V}_{\mathrm{ON}}$ increases with $\mathrm{V}_{\mathrm{A}}$, due to the increase of the physical thickness increase of $\mathrm{TiO}_{2-x}$ films. The obvious shift of $\mathrm{V}_{\mathrm{ON}}$ towards lower potentials indicates the ease of generate defects in the $\mathrm{TiO}_{2-x}$ grown by anodic oxidation. While the presence of defects in the $\mathrm{TiO}_{2-x}$ films could be a nuisance when using them as gate dielectric in electronic devices, when implemented in MIM based memristors the presence of defects in the TMO insulating film is expected to favor atomic rearrangements, facilitating the observation of RS. 

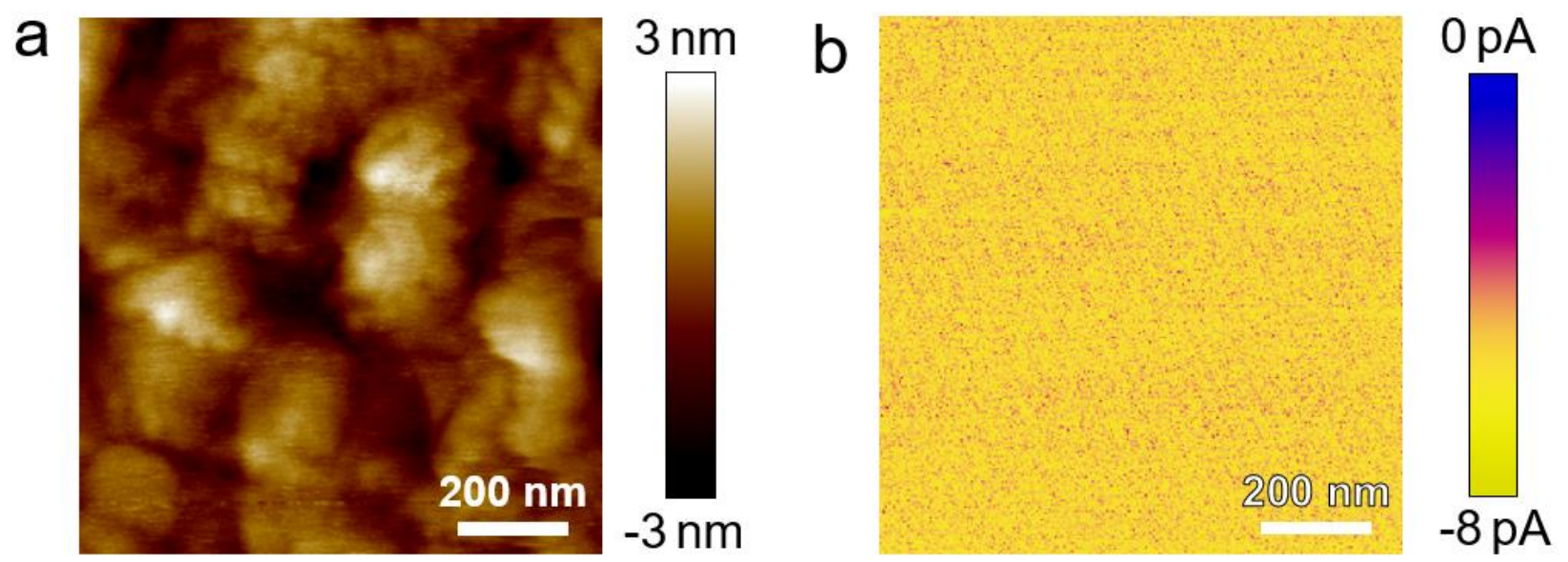

Supplementary Figure S3: CAFM topographic map (a) and corresponding current map (b) of 10 $\mathrm{nm} \mathrm{TiO}_{2-x} / \mathrm{Ti}$ device. A gentle scan bias $(-0.5 \mathrm{~V})$ is applied to the $\mathrm{TiO}_{2-x} / \mathrm{Ti}$ sample to prevent the dielectric breakdown of the $\mathrm{TiO}_{2-x}$ film. The bias is applied to the Ti substrate with tip grounded. As it can be observed, the $\mathrm{TiO}_{2-x}$ exhibits high electrical homogeneity. 

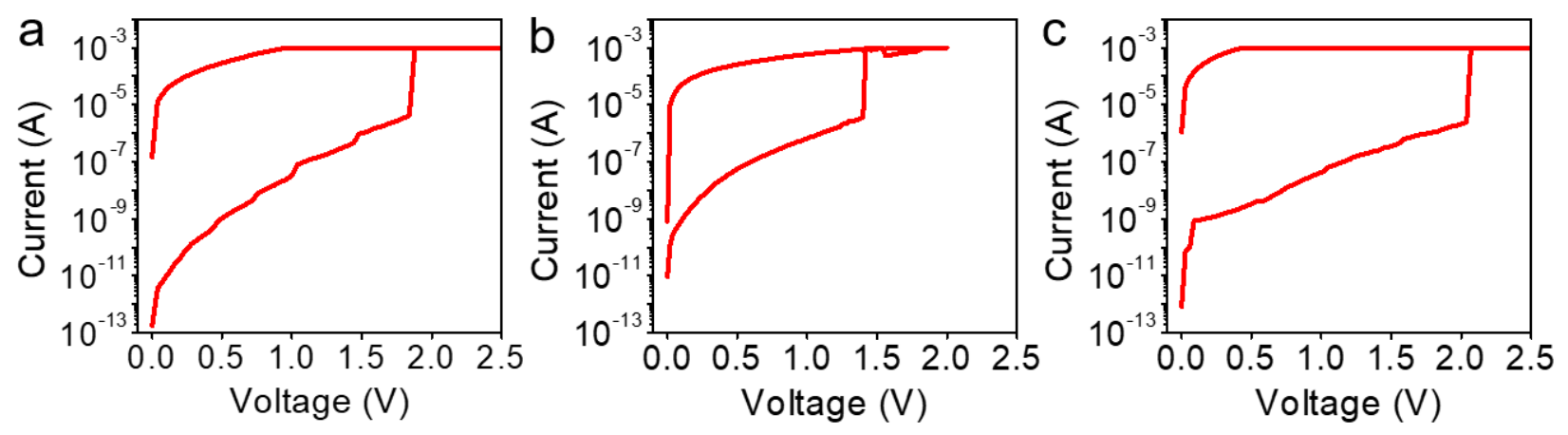

Supplementary Figure S4: Forming curves of $100 \mu \mathrm{m} \times 100 \mu \mathrm{m} \mathrm{Pt} / \mathrm{TiO}_{2-x} /$ Ti devices in Figure 1 (d), (e) and (f).

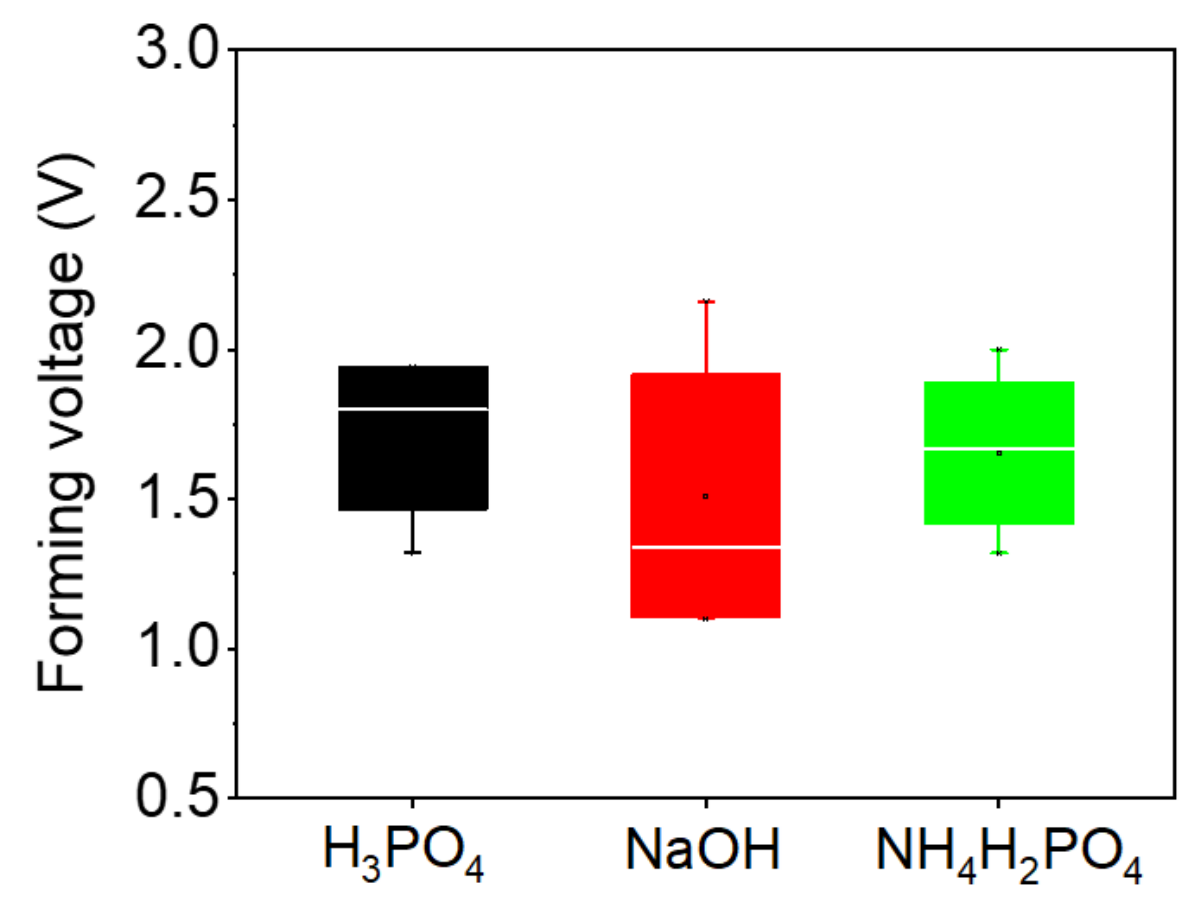

Supplementary Figure S5: Statistics of forming voltages of $100 \mu \mathrm{m} \times 100 \mu \mathrm{m} \mathrm{Pt} / \mathrm{TiO}_{2-x} / \mathrm{Ti}$ devices under different anodizing electrolytes $\left(\mathrm{V}_{\mathrm{A}}=2.5 \mathrm{~V}\right)$. Ten different devices have been tested under each electrolytes. 


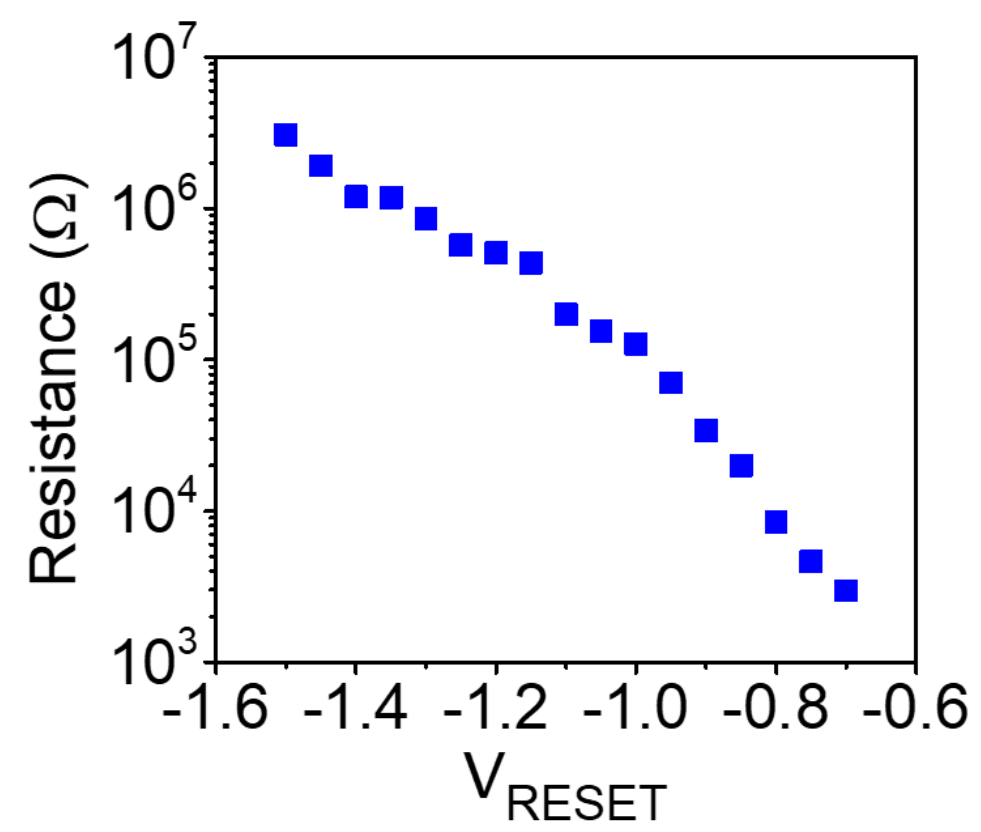

Supplementary Figure S6: Resistance vs $\mathrm{V}_{\text {RESET }}$ plot extracted form Figure 2c, the resistance of $\mathrm{Pt} / \mathrm{TiO}_{2-x} / \mathrm{Ti}$ memristive device shows a decreasing trend when higher reset voltages (from $-0.7 \mathrm{~V}$ to $-1.5 \mathrm{~V}$ ) are applied.

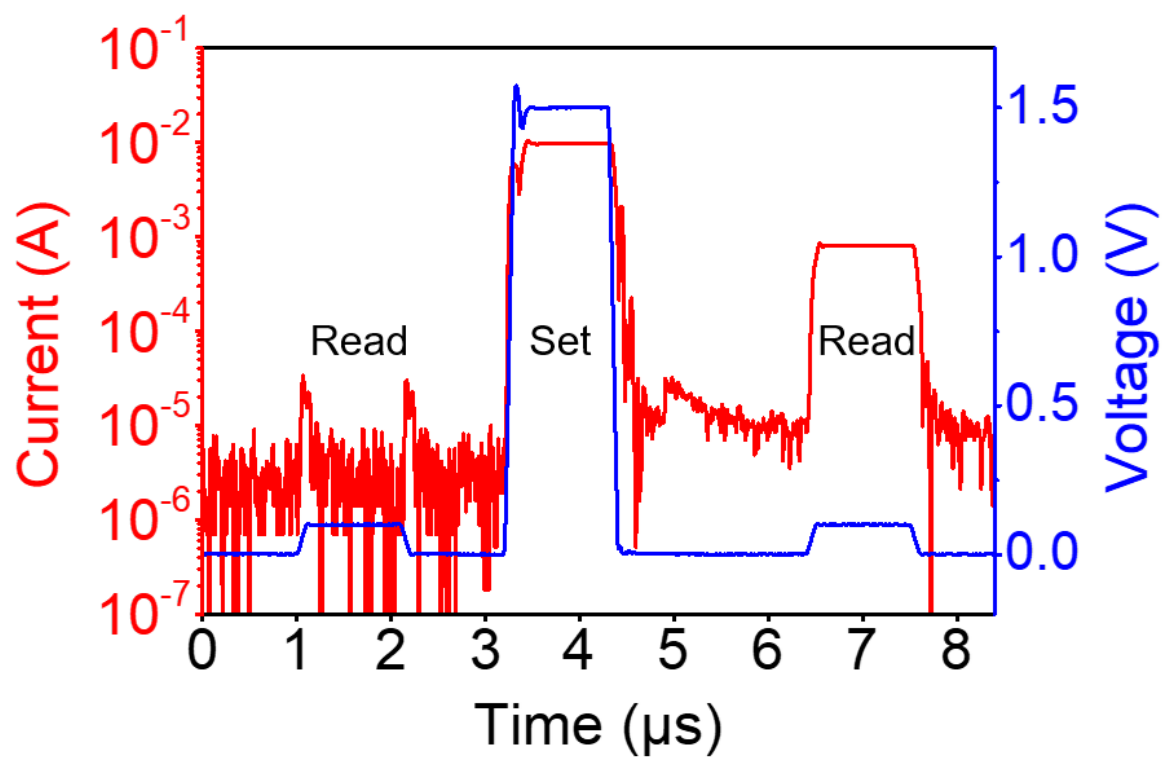

Supplementary Figure S7: Pulse set of Pt/10 nm TiO $2-x /$ Ti memristive device shown in Figure 4. After applying a $2 \mathrm{~V} / 1 \mu$ s set pulse, the $\mathrm{I}_{\mathrm{LRS}} / \mathrm{I}_{\mathrm{HRS}}$ (read by $0.1 \mathrm{~V} / 1 \mu \mathrm{s}$ pulses) is higher than 100 . 

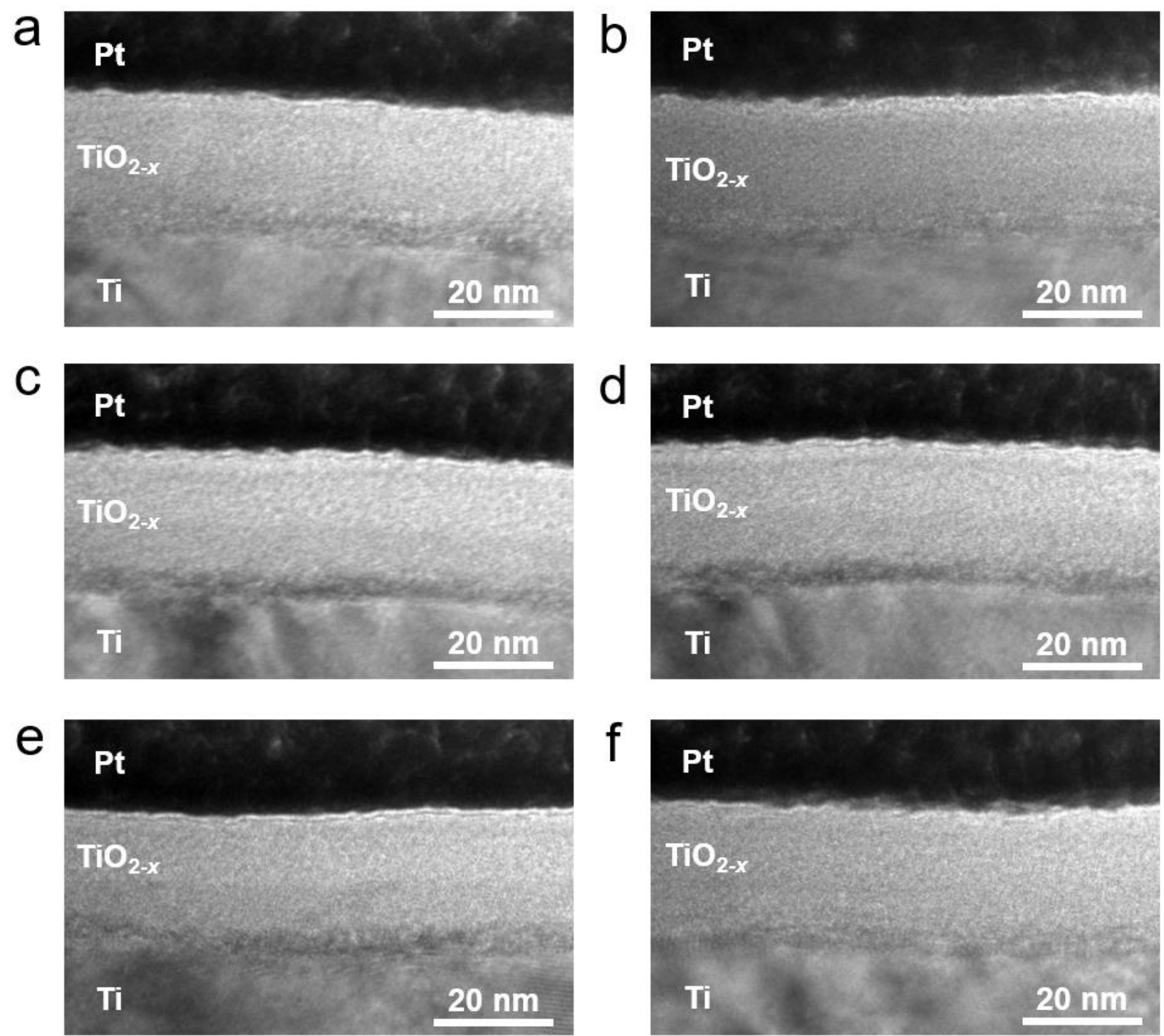

Supplementary Figure S8: Consecutive cross section TEM images collected in stressed Pt/anodic $\mathrm{TiO}_{2-x} / \mathrm{Ti}$ memristive device. All the TEM images show clearly the interface changes between $\mathrm{TiO}_{2-x}$ and Ti layers, suggesting the presence of interfacial reaction under external electrical stimuli. 